\title{
Het oudste Nederlands literair tijdschrift op de wereldwijde stekkerdoos: de webarchivering van De Opkamer (1994-2000)
}

\section{Abstract}

De Opkamer was probably the Netherlands' first online digital literary journal, residing on the web from I994 to 2000 . This article is an account of the search for the site's web archive, in which we reflect on the changing role of a heritage institution curator in locating, collecting and preserving born digital heritage in our current era.

TREFWOORDEN: online literatuurkritiek; internetgeschiedenis; webarcheologie; webarchivering

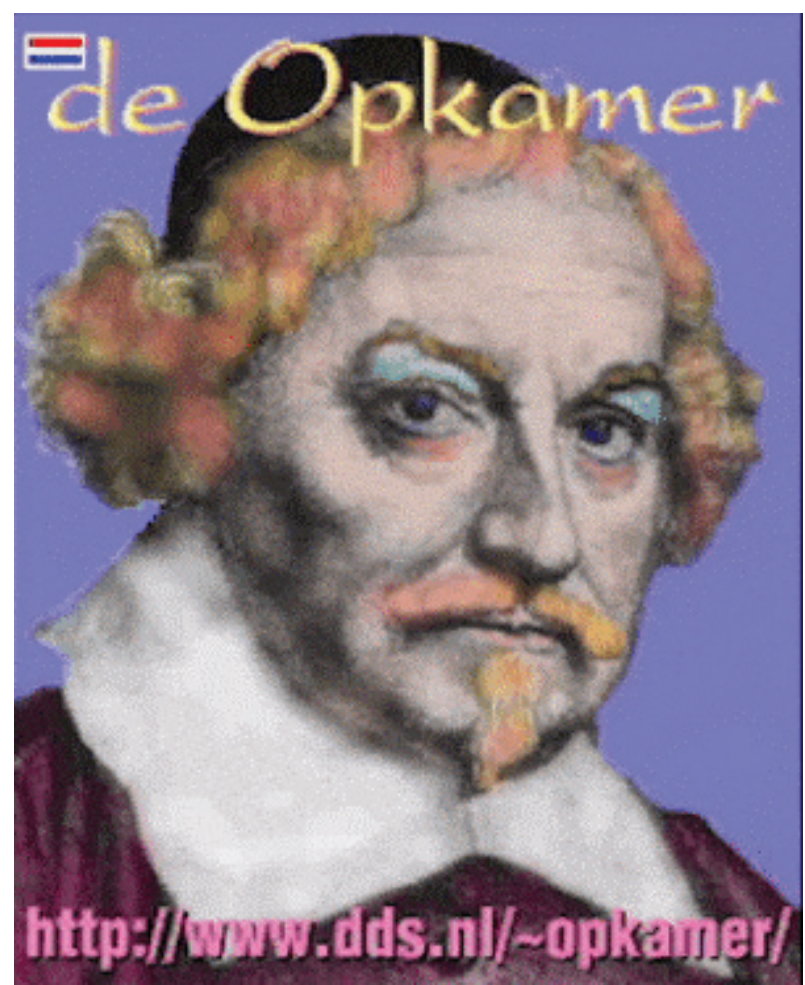

Afbeelding 1. Logo van De Opkamer op De Digitale Stad. 
Het literaire tijdschrift De Opkamer werd in 1994 geboren als homepage met die naam van de Amsterdamse schrijver, fotograaf en webmaster Hans van der Kamp bij de Nederlandse

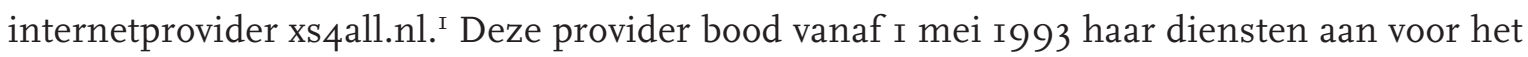
gewone publiek. ${ }^{2}$ Het was daarmee het eerste bedrijf van Nederland dat particulieren toegang bood tot het internet en daarnaast de mogelijkheid gaf om een homepage te publiceren op het web. ${ }^{3}$ Veel internetpioniers, waaronder Van der Kamp, brachten hun eerste homepage onder op deze 'wereldwijde stekkerdoos' en lieten zo hun eerste 'digitaal geboren' sporen achter op het wereldwijde web. Op de oorspronkelijke homepage De Opkamer stonden verhalen en digitale spotprenten. In die zin leek deze site nog het meest op de klassieke literaire publicatie op papier.

De homepage werd een succes: steeds meer verhalen, ook van andere auteurs, verschenen in digitale vorm op de site. Ook vormde zich een redactie rondom de eigenaar van de homepage, bestaande uit Van der Kamp, Theo Gaasbeek, Marten van de Kraats en heel kortstondig Dolf Dukker.4 Langzaam veranderde de persoonlijke homepage in iets dat de kenmerken kreeg van een online literair tijdschrift.5 Dergelijke vroege websites als De Opkamer kunnen we 'webincunabelen' of 'webwiegedrukken' noemen, analoog aan het eerste drukwerk, omdat ze de overgang markeren tussen het traditionele papieren drukwerk en de nieuwe digitale publicaties die op het web verschenen. ${ }^{6}$

De spanning tussen een klassiek gedrukt literair werk en een digitaal gedistribueerd literair experiment kwam ook tot uiting in de archaïsche naam 'Opkamer', een in onbruik geraakt Nederlands woord dat oorspronkelijk een wat hoger gelegen kamer in een traditionele boerenhoeve aanduidde. De redactie zelf heeft de betekenis van de naam en het doel van het tijdschrift in een van de eerst verschenen edities in 1995 krachtig uit de doeken gedaan:

Geachte bezoeker,

De Opkamer is een proefopstelling voor een tijdschrift.

Zoals mijnheer Reve meer dan eens een aankomend schrijver eraan herinnerd heeft dat er al genoeg boeken zijn, zo zal de gemiddelde wandelaar op het Internet zien dat er aan tijdschriften eveneens geen gebrek is.

Aan 'sites', 'homepages' en 'webpages' ook al niet.

Waarom dan toch de Opkamer?

Uit nieuwsgierigheid. Om te kijken wat de lagere productiekosten van een blad op het net kunnen betekenen voor een kleinschalig, op het Nederlandse publiek gericht, medium. Men hoeft geen doemdenker te zijn om te constateren dat de Nederlandse cultuur uitermate oninteressant is voor bladenmakers die zich meer en meer op heel Europa gaan richten.

Vandaar dat de keuze van de titel voor dit tijdschrift niet gevallen is op 'CyberSurf Blues' of 'Infobahn Haltestelle', maar op een Nederlands woord dat morsdood is. Dus flikker uw skateboard aan de kant, kneed uw kauwgom tot een balletje, plak het onder de vensterbank en breng een bezoek aan de Opkamer!7 


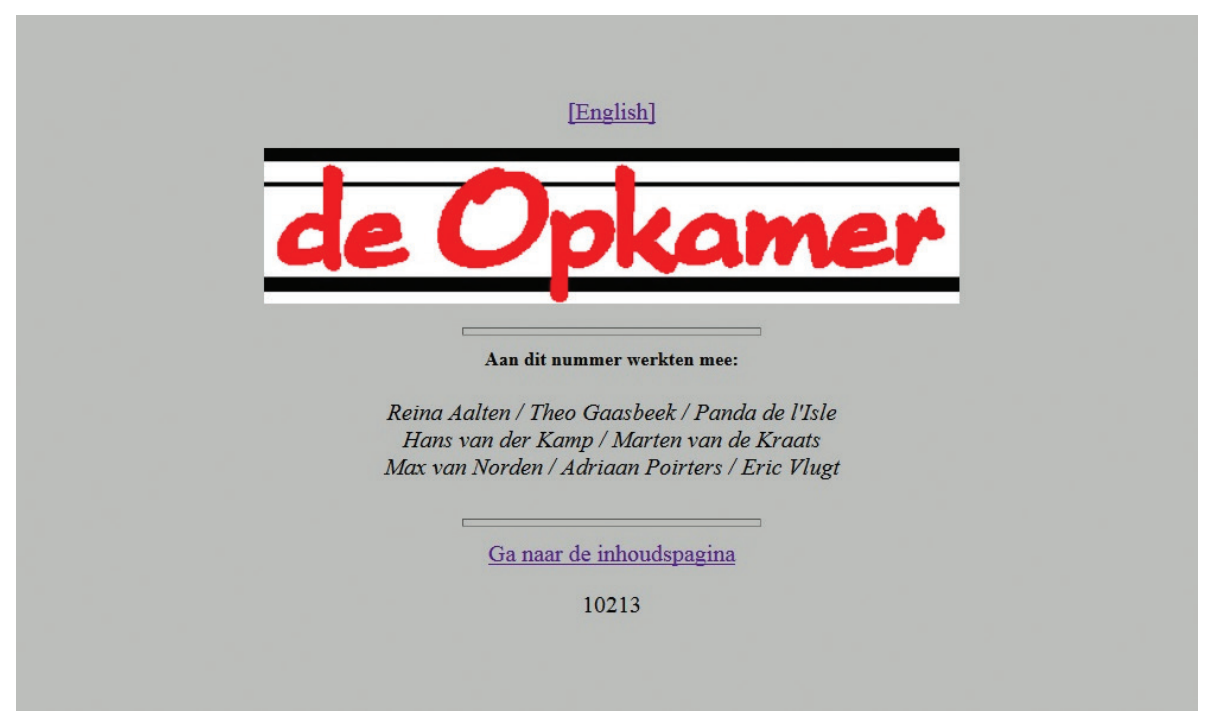

Afbeelding 2. Screenshot van één van de eerste edities van De Opkamer in 1995.

De oorspronkelijke maker van deze site, Van der Kamp, ging steeds meer gebruik maken van de mogelijkheden die html-code bood voor de opmaak, indeling en inhoud. Doordat de technische mogelijkheden niet meer werden beperkt door papier, inkt en prijzige analoge ontwerp- en druktechnieken, kon worden geëxperimenteerd met frequentere verschijningen (bijvoorbeeld het citaat van de dag), audio ('het stemmenkabinet', met geluidsopnames van gesproken fragmenten door auteurs zelf) al dan niet bewerkte foto's en bewegende afbeeldingen, kleur en digitale vormgeving. Daarnaast was het spel met virtuele auteurs waarvan de lezer niet geheel duidelijk was of het persoon ook IRL (in real life) bestond of dat de maker van het tijdschrift zich achter verschillende virtuele personen verschuilde (met een eigen digitaal portret), een spannend en verfrissende nieuwe manier om met pseudoniemen, identiteiten en authenticiteit om te gaan. ${ }^{8}$

Juist door die ontwikkeling van inhoud, opmaak en eenvoudige verspreiding kon in mei I995 voor het eerst gesproken worden van een online literair tijdschrift, ook al was het niet bij aanvang de bedoeling geweest dat een dergelijk digitaal periodiek zou ontstaan. Met deze webpublicatie was het eerste digitale tijdschrift voor Nederlandstalige literatuur op het web een feit. De redactie lijkt vanaf het begin al bewust te zijn geweest dat met deze digitale geboorte ook literaire geschiedenis werd geschreven. Dit blijkt uit een bijdrage van redactielid Dolf Dukker op de Forumpagina van De Volkskrant op 2I juni I995 met de volgende kop: "In digitaal tijdperk is drukwerk voorbestemd voor het antiquariaat" (sic!).9 Alleen titels die de dominantie van het digitale dataverkeer tot uitgangspunt kiezen, zullen in de marge kunnen overleven, aldus de auteur.

Mijn eigen zoektocht naar De Opkamer kwam na mijn aanstelling als conservator digitale collecties bij de Koninklijke Bibliotheek - Nationale Bibliotheek van Nederland (KB) bij de afdeling collecties in februari 20I8. De KB is in 2007 begonnen met het selecteren en archiveren van websites voor de opbouw van de webcollectie. In de loop der jaren zijn daarbij 15.000 sites in de collectie opgenomen als onderdeel van de Collectie Nederland. Tot dan toe was er nooit 


\section{INTERNET VOOR SCHATJES}

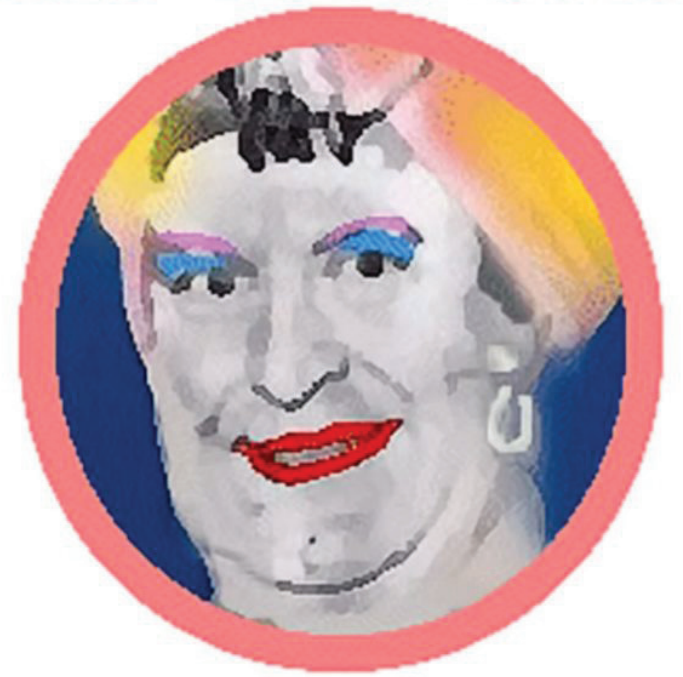

\section{EEM CURSUS VAN UVI UIEBMEESTERES H.}

Afbeelding 3. Webmeesteres K., één van de virtuele redactieleden.

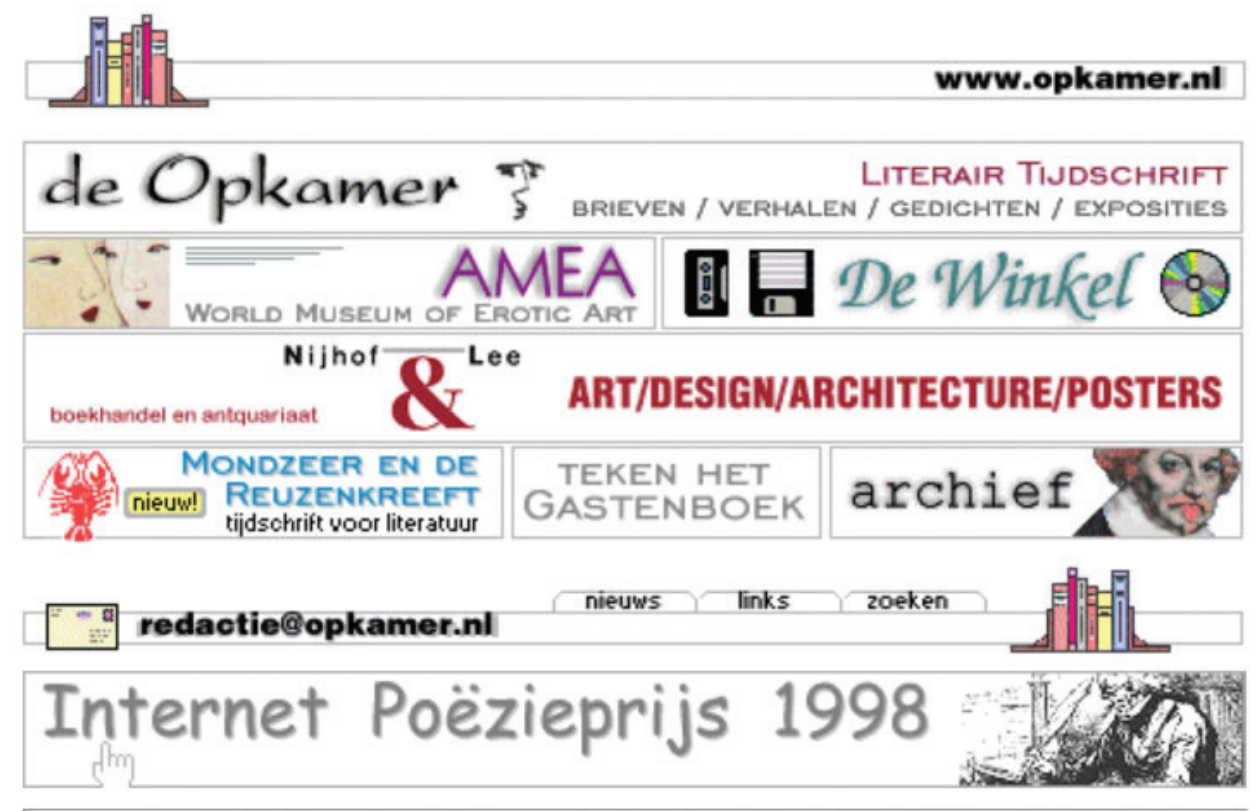

\section{Hef Citaat van de Dag}

the best of Europe...
Europe Online

Afbeelding 4. De Opkamer in 1998. 
retrospectief gecollectioneerd, in de zin dat systematisch websites van en over Nederland en daterend voor 2007 waren opgespoord, geselecteerd en gearchiveerd. Doordat nooit achterom was gekeken bij het webarchiveren, was een gat ontstaan in de born digital collectie wat betreft de periode I994-2007. Veel cultuurhistorisch belangrijke websites bleken nooit te zijn bewaard, zoals bijvoorbeeld de meeste oudere particuliere homepages, een groot deel van de Nederlandse blogosfeer en sites van minderheden.

Ik ben daarom op zoek gegaan naar in cultuurhistorisch opzicht belangrijke sites uit de periode voor 2007 die in de collectie zouden moeten worden opgenomen. Mijn speciale aandacht hadden sites uit de periode I994-2000, die eerste wilde jaren van het Nederlandse internet die gekenmerkt werd door torenhoog optimisme, onstuimige groei van het Nederlandse web en een explosie van digitale creativiteit. ${ }^{10}$ In deze periode ontstonden de eerder genoemde webincunabelen, die belangrijke bronnen kunnen zijn van de technische en inhoudelijke ontwikkeling van de Nederlandse webcultuur. Het voorjaar 2000 is ook een belangrijk moment geweest voor het vroege Nederlandse web, omdat in die tijd de internetzeepbel knapte. Veel internetbedrijven gingen toen failliet, websites verdwenen en aan het creatieve optimisme van het begin kwam een einde. De webcultuur werd vanaf dat moment zakelijker en minder experimenteel, maar kon misschien ook wel daardoor een onlosmakelijk onderdeel van het dagelijkse leven worden. Paradoxaal genoeg hield de bloeiperiode op toen het internet raakte ingeburgerd, zoals Carolien van de Berg in een scriptie al vaststelde. ${ }^{\text {II }}$

Mijn eerste kennismaking met De Opkamer was bij het lezen van een artikel over de overleden dichter Menno Wigman dat op 7 februari 20I8 verscheen in De Groene Amsterdammer. De volgende passage trok mijn aandacht:

Ik kom Wigman voor het eerst 'tegen' in De Opkamer, een van de eerste Nederlandse literaire tijdschriften op internet, onder redactie van Hans van der Kamp. Het staat allemaal nog in de kinderschoenen, internet en literatuur, maar De Opkamer is klassiek en sober vormgegeven en er is veel moois te lezen, onder andere een gedicht van Wigman, die in 1997 gedebuteerd is met 's Zomers stinken alle steden. ${ }^{12}$

Het oorspronkelijke webadres van De Opkamer www.opkamer.nl bleek inmiddels overgenomen door een bedrijf dat handelt in domeinnamen en verwijst door naar een erotische site. ${ }^{\mathrm{I} 3}$ Een snelle blik op de gearchiveerde versies in de webcollectie van het Internet Archive leerde dat de site of helemaal niet, of slechts fragmentarisch was bewaard, zoals dat met veel Nederlandse webincunabelen in het Internet Archive het geval is. ${ }^{\mathrm{I}}$

Een gearchiveerd deel van de site dat mijn onmiddellijke aandacht trok, was de online winkel. ${ }^{15}$ Volgens de redactie van de Opkamer was deze pagina opgezet om inkomsten te trekken, omdat digitale producten op het web lastig te verkopen zijn. ${ }^{6}$ De kunst was om fysieke producten aan te bieden die niet van papier waren (zoals het 'houthakkersgilde' van de traditionele auteurs en uitgevers die aan de man brachten, in de woorden van Van der Kamp), maar dragers waren van digitale bestanden van het literaire werk. Voorbeelden hiervan waren audio-cd's met opnames van schrijvers en een cd-rom met een bestand van het Amerikaanse 
Starr Report dat bronnen bevatte over de dreigende afzettingsprocedure van President Bill Clinton, samen met 500 spotprenten. ${ }^{17}$

Deze denkwijze over de verkoop van dergelijke producten hangt ook weer samen met de overgang tussen analoog en geboren digitaal in die periode: omdat oplossingen als betaalmuren, online betalingswijzen en digitale abonnementsvormen nog niet bestonden, moesten andere manieren worden gevonden om de creatieve vruchten van het digitale werk in klinkende munt om te zetten. De redactie sprak zelf van het 'overleven in de digitale hongerwinter', omdat zij voorzagen dat het internet ooit veel geld op zou gaan leveren, maar dat dit op korte termijn in elk geval voor een literair tijdschrift niet het geval zou zijn.

Het meest interessante deel van de digitale winkel was het gedeelte waar 'zips' werden aangeboden: gecomprimeerde versies van de online website die op een drager werden bewaard. ${ }^{18}$ Op een pagina met een afbeelding van een floppy disk werd een van de eerste versies van $D e$ Opkamer (de 'proefopstelling' of De Opkamer O.I) uit mei I995 als verzamelobject verkocht als bestand van één $\mathrm{MB}$ op een drie inch diskette. ${ }^{19}$

De tweede gearchiveerde versie was de zogenaamde DDS-freeze: geïnspireerd door de archiefversie van De Digitale Stad Amsterdam (DDS) die de beheerders op I5 januari I996 hadden gemaakt, had de redactie van De Opkamer een back-up van het digitale tijdschrift op vijf diskettes vereeuwigd. Volgens de beschrijving op de site was dit: 'een tijdschrift in hypertext dat off-line te starten is, verpakt in een luxe cassette. Genummerde oplage van 75 stuks. ${ }^{20}$ De versie van de winkel in het Internet Archive is volgens de time stamp gearchiveerd op I3 augustus I997, maar de pagina dateert zeker uit begin I996. ${ }^{21}$

Daar het oudste webarchief van Nederland genaamd Archipol van het Documentatiecentrum Nederlandse Politieke Partijen (DNPP) pas in 2000 begon met archiveren en de eerder genoemde DDS-freeze uit I996 dateert, zou deze gearchiveerde versie van de site uit I995 wel eens het oudste webarchief van een Nederlandse site kunnen zijn.

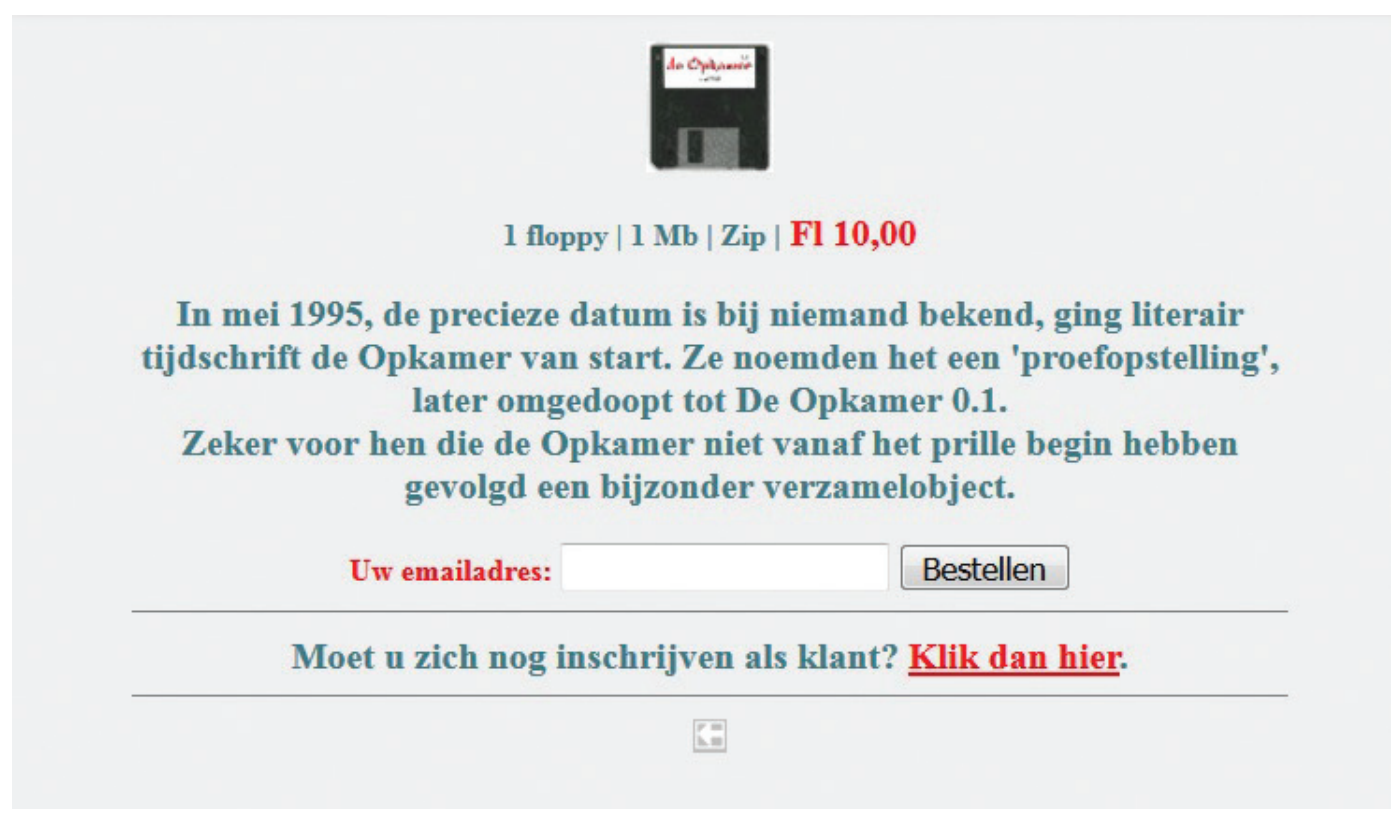

Afbeelding 5. De gearchiveerde versie als verzamelobject aangeboden in de webwinkel. 


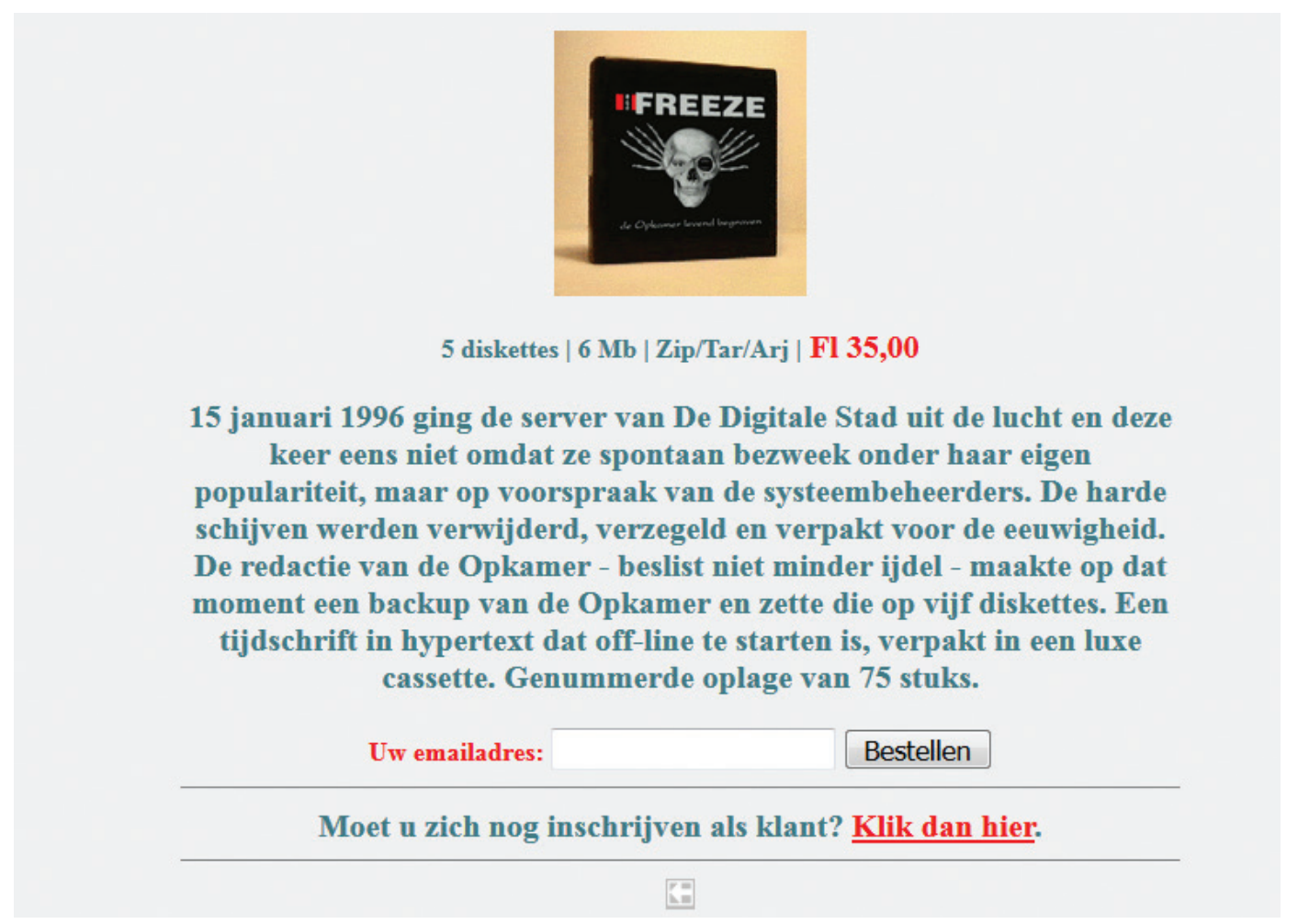

Afbeelding 6. Tweede gearchiveerde versie als verzamelobject aangeboden in de webwinkel.

Na deze digitale ontdekking nam ik begin 2018 vol spanning contact op met de heer Van der Kamp. De floppy uit de webshop kon een unieke aanwinst voor de born digital collectie van de KB zijn en wellicht ooit in de expositie topstukken kunnen worden tentoongesteld als tastbare, zichtbare en authentieke drager van een webincunabel. Na digitaal en telefonisch contact was de gevraagde floppy nog niet ter sprake gekomen, maar was de webmaster wel zonder dat ons te laten weten - weer begonnen met het maken van een reconstructie van de oude site op een nieuwe URL: opkamer.org.

Net als dat het oorspronkelijke literaire tijdschrift een vernieuwend digitaal experiment was, werd de gearchiveerde versie opnieuw een unieke vorm van digitaal erfgoed waar nieuw leven in werd geblazen. De webmaster heeft niet alleen de oude versies van de site opnieuw online gezet samen met digitale bronnen op basis van de bewaarde datadragers, maar daarbij ook een uitgebreide beschrijving gegeven van elke doosvondst of opmerkelijk detail dat uit zijn geheugen naar boven kwam in een aantal blogposts. ${ }^{22}$ Hiermee biedt hij unieke contextinformatie bij de digitale bronnen die onontbeerlijk zal blijken te zijn voor toekomstige literatuurhistorici en die op geen enkele andere manier in de toekomst zal te achterhalen zijn.

Webarchiveren is een vorm van het bewaren van erfgoed waarbij digitale data van het live web wordt gehaald en vervolgens zo authentiek mogelijk wordt opgeslagen, zodat dit in de toekomst offline kan worden geraadpleegd. ${ }^{23}$ Ondanks dat daarom de bron wordt geconstrueerd door de archiefvormer of het webarchief zelf, is het natuurlijk niet de bedoeling dat de bewaarder op de een of andere manier onderdeel wordt van de bron zelf, anders dan de aan de bron toegevoegde metadata. Een onderdeel van het 'analoge webarchiveren' van de Opkamer was ook een bezoek aan de webmaster en diens collectie zelf door het team webarchivering van de KB, 


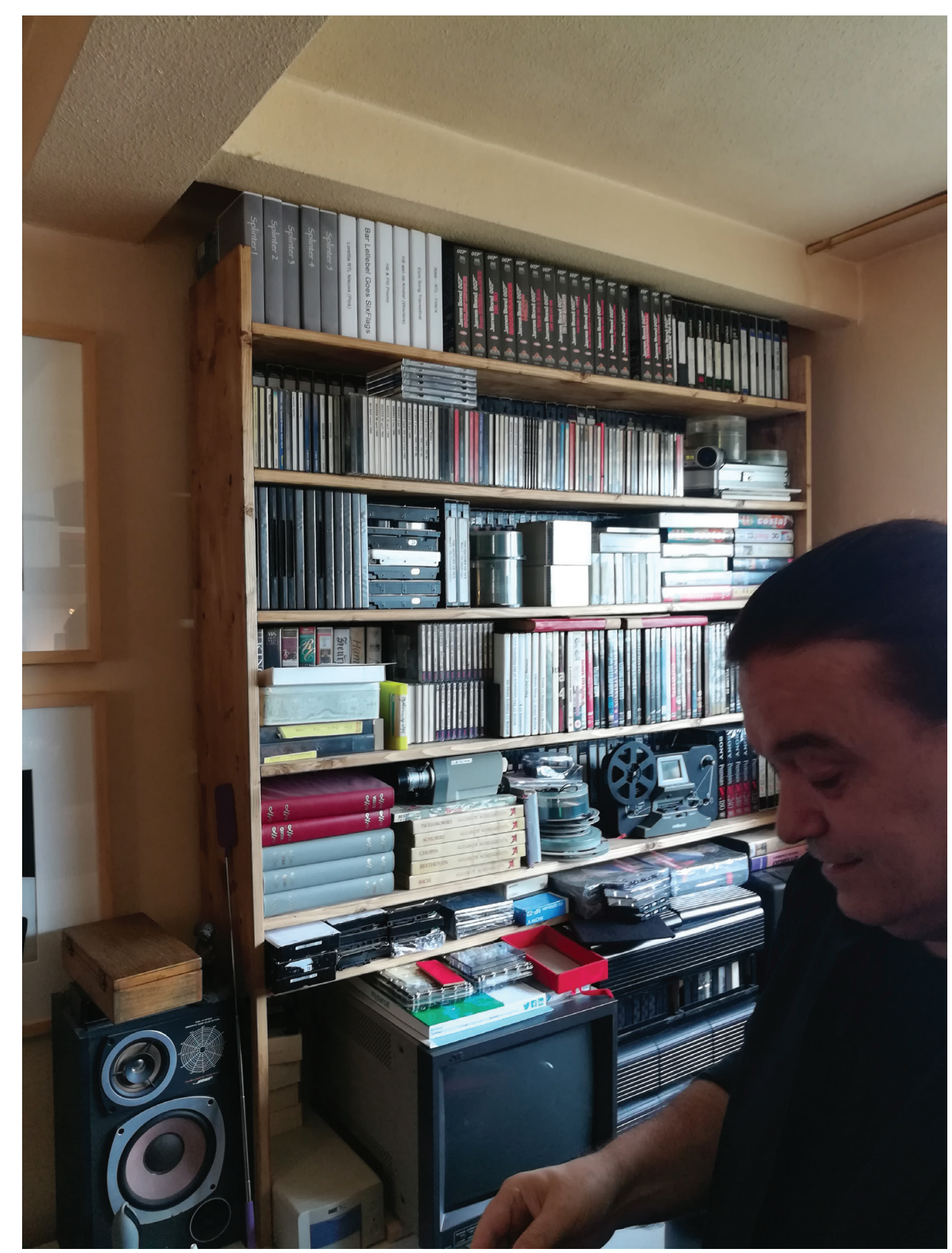

Afbeelding 7. Dhr. Hans van der Kamp met zijn collectie datadragers (Foto: Kees Teszelszky).

bestaande uit een stagiair, de dienstcoördinator webarchivering en ondergetekende. ${ }^{24}$ Uiteindelijk kwam een weerslag van onze gesprekken in de blogposts en de uitleg op de site terecht, die daarna in het webcollectie van de KB terechtkwam. ${ }^{25}$ Tot onze grote verrassing bleken wij zo als webarchivarissen en webarcheologen zelf een onderdeel te zijn geworden van de gearchiveerde versie van de digitaal geboren bron.

Hoe is de zoektocht naar het geboren digitale topstuk van de Nederlandse online literatuur afgelopen? De floppy disk bleek tot onze ontmoeting met de maker in 20 I 8 enkel een virtueel 

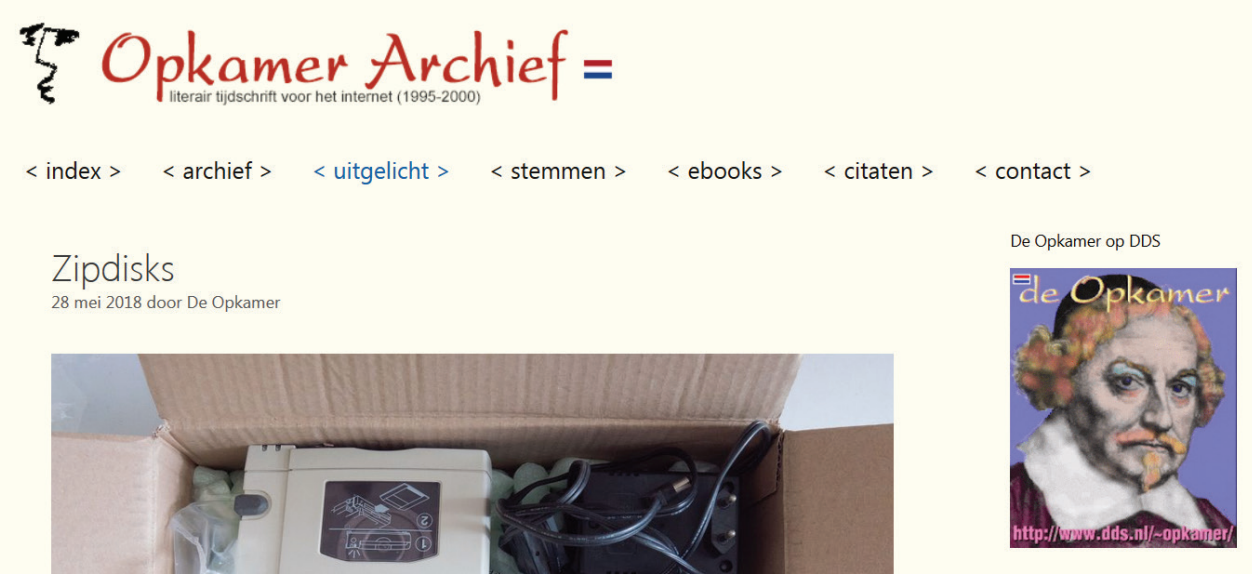

Afbeelding 8. Screenshot van blog op website De Opkamer.

bestaan te hebben geleid en nooit de diskdrive te hebben verlaten. Daar er nooit een online bestelling was geplaatst, was het aangekondigde archief uiteindelijk nooit fysiek verschenen. De data (uit 1995) was gelukkig wel bewaard gebleven in de collectie van de maker. ${ }^{26}$ De gereconstrueerde versie van de site uit 2018 is uiteindelijk 23 jaar later het beloofde unieke verzamelobject geworden, 'zeker voor mensen die de Opkamer vanaf het begin niet hebben gevolgd', zoals de verkooptekst uit de jaren '9o luidde. ${ }^{27}$ De KB heeft de archiefversie niet gekregen in de vorm van een floppy, maar probeert wel de bestanden alsnog van oude datadragers af te halen. Bovendien archiveert de KB de gereconstrueerde versie van de site met de contextinformatie die door de heer Van der Kamp is toegevoegd.

Kortom: De Opkamer is niet alleen het eerste online digitale literaire tijdschrift van Nederland geweest, maar ook een bijzondere casus van het archiveren van geboren digitaal Nederlands erfgoed. Tot slot moeten we de mens achter de digitale data niet vergeten. De maker Hans van der Kamp is niet alleen een begenadigd webmaster en fotograaf, maar bovenal een goed schrijver. Zo heeft hij als enige in Nederland zowel de PC (Propria Cures) Onthooftprijs als de Keefmanbokaal gewonnen (een literaire prijs van literair studentenblad Propria Cures ter nagedachtenis van Jan Arends). ${ }^{28} \mathrm{Ik}$ wil daarom dit stuk afsluiten met de welbekende aanmoediging van Propria Cures als boodschap aan de auteur: 'schrijft u nog eens wat'. Hoe meer wordt geschreven over De Opkamer, des te beter zal deze kunnen worden bewaard.

\section{Notes}

I. http://xs4all.nl/ hvdkamp (inmiddels offline). De inhoud van de site is niet bewaard gebleven in het Internet Archive: de vroegste versie bevat een verhuisbericht naar de URL opkamer.nl. Zie: https://web.archive. org/web/I996ı2I9I3I500/; http://www.xs4all.nl:80/ hvdkamp/ (alle in de voetnoten genoemde links: laatst geraadpleegd op I7 mei 20I9).

2. https://www.xs4all.nl/over-xs4all/wie-wij-zijn.htm.

3. Jak Boumans, Toen digitale media nog nieuw waren. Pre-internet in de polder (1967-1997) (Gorredijk: Media Update Vakpublicaties, 20II), 236, 248-252.

4. Mededeling van de heer Van der Kamp (e-mail ontvangen op I7 mei 20I9).

5. De site is gereconstrueerd op: http://www.opkamer.org/. 
6. De term 'webincunabel' werd rond 2004 bedacht door een anonieme bibliothecaris werkzaam bij de Bibliothèque Nationale de France (BNF). Zie: http://www.bnf.fr/fr/professionnels/dlweb_cooperation/a.depot_legal_internet_cooperation_nationale.html.

7. http://www.opkamer.org/wp-content/opkar/PARDON.HTM.

8. http://www.opkamer.org/webmeesteres-k-en-dds-freeze/.

9. https://resolver.kb.nl/resolve?urn=ABCDDD:oı0870869:mpeg2i:poiı.

Io. Kees Teszelszky, 'Web Archaeology in The Netherlands: The Selection and Harvest of the Dutch Web Incunables of Provider Euronet (I994-2000),' Internet Histories 3, no. 2 (2019): I80-I94, DOI: 10.1080/24701475.2019.160395I.

II. Marc van Oostendorp, Een toekomst zonder verleden, 22 februari 20IO, https://www.neerlandistiek.nl/2010/02/ een-toekomst-zonder-verleden/.

I2. Alfred Schaffer, "Godverdedomme”, De Groene Amsterdammer, 7 februari 20I8, https://www.groene.nl/artikel/ godverdedomme.

I3. De oorspronkelijke URL van de site was www.opkamer.nl verwijst door naar de erotische site oops.nl en is in bezit van idprof.nl (12 mei 20I9).

I4. https://web.archive.org/web/2000I025001942/; http://www.dds.nl/ opkamer/freezor.htm.

I5. https://web.archive.org/web/i99708ıı080339/; http://www.opkamer.nl/winkel/.

I6. http://www.opkamer.org/starr-report/.

I7. http://www.opkamer.org/starr-report/; https://en.wikipedia.org/wiki/Starr_Report.

I8. https://web.archive.org/web/i997081313574I/; http://www.opkamer.nl/winkel/zip.htm.

I9. https://web.archive.org/web/I9970813145204/; http://www.opkamer.nl/winkel/zipoo2.htm.

20. https://web.archive.org/web/I99708I3I45I43/; http://www.opkamer.nl/winkel/zipoor.htm.

2I. https://web.archive.org/web/I997081313574I/; http://www.opkamer.nl/winkel/zip.htm.

22. http://www.opkamer.org/category/blog/.

23. Zie: Barbara Sierman en Kees Teszelszky, 'How Can We Improve our Web Collection? An Evaluation of Webarchiving at the KB National Library of the Netherlands (2007-20I7),' Alexandria: The Journal of National and International Library and Information Issues (20I7), https://doi-org.proxy-ub.rug.nl/IO.II77/09557490I7725930.

24. Voor een impressie van het analoge archief, zie: http://hvdk.com/archives/4336.

25. http://www.opkamer.org/category/blog/.

26. Interessant is dat van de vroegste versies van de homepage uit 1994 nooit offline archiefversies zijn bewaard gebleven, omdat de inhoud rechtstreeks naar de server werd geschreven en op deze manier werkelijk digitaal geboren was. Uit correspondentie met de heer Van der Kamp: 'De eerste Opkamerpagina's voorzien van een colofon voor redactie werden "aan de prompt" geschreven, naar ik meen in Pico. De graphics werden off-line (sic) geproduceerd in Paint Shop Pro 3. Mijn kennis ging indertijd niet ver genoeg om pagina's die aan de prompt geschreven waren, dus op de server zelf waren geschreven met behulp van Pico of een ander programma te backuppen. Ik wist ook nog niet goed hoe ik met een FTP-client moest omgaan en leerde pas in I995 hoe je in Notepad HTML kon schrijven' (e-mail ontvangen I7 mei 20I9).

27. https://web.archive.org/web/I9970813145204/; http://www.opkamer.nl/winkel/zipoo2.htm.

28. http://www.propriacures.nl/word-pc-redacteur/.

\section{Biografie}

Kees Teszelszky (I972) studeerde politieke wetenschappen in Leiden en Oost-Europese studies in Amsterdam en is gepromoveerd op cultuurgeschiedenis aan de Rijksuniversiteit Groningen (2006). Sinds 20I2 doet hij onderzoek naar webarchieven. Hij is conservator digitale collecties bij de KB. Hij houdt zich bezig met de selectie, opslag en beschikbaarstelling van born digital bronnen, in het bijzonder websites, online nieuws en e-books. Daarnaast is hij een enthousiast webarcheoloog en doet projecten als het in kaart brengen van het Nederlandse Nationale webdomein, de Nederlandse blogosfeer en Nederlandse webincunabelen. 